\title{
Structure Analysis and Optimization Countermeasures of Logistics Cost of Agricultural Product in China
}

\author{
Rui Du ${ }^{*}$, Xiaohua Hou, Juan Huang \\ Shaanxi Institute of International Trade \& Commerce, Xi’an, 712046, China \\ *Corresponding Author: Rui Du
}

Keywords: Agricultural product logistics, Logistics cost, Cost accounting

\begin{abstract}
In recent years, the price of agricultural products has risen greatly, which directly affects the quality of people's living standards. The main reason for the price increase is that the cost structure of agricultural products is irrational. This paper analyzes the key factors influencing the structure of logistics cost of agricultural products in China, and puts forward some countermeasures and suggestions from the aspects of simplifying circulation links, constructing the information platform and improving logistics infrastructure to reduce the logistics cost of agricultural products.
\end{abstract}

\section{Introduction}

The cost of logistics in our country is too high to weaken the market competitiveness of agricultural products. The cost of agricultural products logistics in China is too high, including transportation, use, field operation and management, processing and selling of agricultural products and so on. In the whole production supply chain, logistics cost is the biggest addition to raw materials outside the project cost, logistics cost is in addition to seeds, pesticide and fertilizer structure of the payment of the cost of projects, but still belongs to the composition of the total cost of agriculture, implementation and management of the logistics cost of agricultural products, can effectively reduce the circulation of agricultural products and reduce the cost. Supply and sales costs in production of agricultural products. The new rural construction logistics system which is matched with the construction of rural infrastructure improvement, agricultural products wholesale market construction and renovation, fresh agricultural products network construction will accelerate the rural logistics system. China is a large agricultural country, but for a long time, the public finance has not pulled enough into the countryside, and the rural logistics system is very backward. With the construction of new countryside and promote, grain logistics, cold chain logistics, green logistics of agricultural products, agricultural logistics will become a bright spot in the development of the logistics industry in China, constantly improve the rural logistics system to improve farmers' income and the added value of agricultural products will play an increasingly important role. The logistics cost structure of agricultural products consists of the following parts: agricultural product production, logistics costs, warehousing costs, transportation costs, information management costs. Whether it is from the economic development and industrial development perspective, should be on the agricultural product logistics cost optimization results, the factors of the logistics cost of agricultural products and mechanism, analyze and control its circulation, quality and efficiency improvement of agricultural products logistics. Under the influence of many factors, the cost structure of agricultural products logistics needs to be optimized.

\section{Key Factors of Logistics Cost of Agricultural Product in China}

Overmany Transit Links. At present, the traditional trading channels of agricultural products in China are complex and various, and the circulation cost is too high. Agricultural products from farmers to the hands of consumers, usually through four or five links. From the producer to the origin 
market, then to wholesalers to sell and market, to retailers, and finally to the consumer. As there are too many intermediate links, each link has its pollution, loading and unloading, transportation, personnel costs, capital costs, profits and so on, leading to an increasing cost. According to the current circulation channels, according to statistics, the cost of circulation accounts for half of the price of agricultural products, while the last kilometer of the circulation accounts for more than half of the cost of circulation. From the urban level wholesale market to the retail market, the cost is the highest link in the entire circulation process. The cost of agricultural products supply, procurement and logistics refers to the logistics costs in the process of purchasing raw materials and auxiliary materials. The cost of agricultural product logistics refers to the costs associated with logistics in the process of production. The cost of agricultural sales logistics refers to the logistics costs resulting from the entry of agricultural products into circulation. The cost of agricultural waste logistics refers to the processing costs of the wastes produced in the process of sale of agricultural products. At present, the logistics structure of agricultural products logistics in China is generally small, low in scale and relatively small in logistics channels. Most agricultural products must go through production and sale, the two wholesale markets to reach the hands of consumers. During the period of many changes, it also improved the logistics costs of agricultural products and increased the losses in the circulation of agricultural products. The frequent transfer and long-distance trafficking of agricultural products have become the main reason for the high cost of logistics and transportation.

Unsmooth Information Flow. At present, the number and application level of modern information technology practitioners in our logistics industry are not high. According to statistics, only one third of enterprises in China have logistics information management system. Although some large wholesale markets in China have initially established information service platforms, the quantity and content of the information provided cannot meet the needs of the market for logistics. Because of the poor information, the supply and demand relationship of middle peasant products in China's wholesale market is in great uncertainty. Price fluctuation in some areas will lead to imbalance between supply and demand in a short time. A heavy snow will lead to a big fluctuation in the prices of agricultural products. This greatly increases the risk of logistics and trading of agricultural products. The scale of rural household production in China is generally small, rural households are too scattered, and no specialized planting base has been formed, and the means of information transmission are backward. Many local governments have not yet established the information platform of agricultural products, farmers' access to outside information rely mainly on television, radio and newspapers and other mass media, the information is not complete, the production is easy to appear the phenomenon of blindly follow. Part of rural enterprises and marketing major although built e-commerce platform, but information on the information platform to know enough, stay in the basic function of agricultural products supply and demand information, price information and display on corporate image. The information platform is slow to update, narrow coverage, limited information flow and high risk. Most of the agricultural logistics enterprises are still mainly manual in all aspects of warehousing, transportation and distribution, and there is no automated information network, which cannot optimize the scheduling and effective allocation. Platform for customers cannot provide inquiries, tracking services, resulting in elongated product flow time. Farmers are in a passive position in the whole process of supply chain and cannot obtain effective supply and demand in a timely manner.

Poor Logistic Facilities. The infrastructure and equipment of agricultural products logistics include the wholesale markets of agricultural products, storage of agricultural products, transportation facilities and facilities. Through the efforts in recent years, although China's agricultural products logistics has a certain development, but there is a big gap between China's agricultural products, transportation, storage, insurance and logistics industry. There is widespread lack of large cold storage preservation and refrigeration equipment, agricultural products distribution outlets in urban and rural logistics system construction lag, poor coordination, low level of technology, resulting in a large number of clothing products in the logistics process for loss is too large and can increase the cost, seriously affecting the value of agricultural products in the process of logistics increment: in our 
country, the circulation costs accounted for the entire cost of general logistics. Toll roads in our country are the most expensive in the world. At present, the wholesale market of agricultural products in China has developed, with many links and high fees, so that the country cannot effectively control the prices of agricultural products through the market. The market of agricultural products is still in the initial stage, and only has the function of centralized trading. It does not have the functions of storage, preservation, logistics and distribution, pesticide residue detection and modern market information. In some rural areas, agricultural exports are restricted without railways and highways. Lack of basic logistics equipment, logistics of agricultural products mainly rely on pickup truck transportation, refrigeration and heat preservation box type refrigerated vehicles only accounted for the province's agricultural products logistics. This causes the agricultural product to decay at the normal temperature. Again, the lack of professional logistics configuration, such as professional handling machinery, special warehouse capacity is not enough, piled up in the open-air logistics enterprises incomplete facilities meet the eye everywhere, a lot of problems, so the loss of agricultural products is bound to increase the cost of logistics.

\section{Optimization Countermeasures of Logistics Cost of Agricultural Product in China}

Reduce Transit Links. As the degree of organization of farmers to solve China's current low agricultural production is highly dispersed, should encourage the circulation of agricultural products, agricultural industrialization leading enterprises, transport enterprises and farmers' cooperatives and other agricultural cooperative economic organizations and farmers cooperation, truly reduce intermediate links, reduce transaction cost. To reduce the cost of circulation of clothing products, the value-added tax should be exempted from the wholesale and retail of vegetables, and the policies of cleaning and reducing the wholesale markets of agricultural products, the urban community food market, the township market and the charging of supermarkets. The personnel of each link to optimize the organizational structure, will make the effect of human output to achieve greater protection. Through the corresponding posts for personnel adjustment, in agricultural products storage and transportation in the implementation of a unified personnel responsible, can be stored and transported in the protection of middle peasants' products throughout the process of monitoring. In the large size handling work, use reasonably can allocate personnel, transport of agricultural products security level is low and cost big problems caused by temporary hiring many low professional level personnel, implement the responsibility system for supervision of personnel, agricultural products storage and transportation to the destination by monitoring the whole process the. Learn from the successful experience of foreign large supermarket chains, farmers' professional cooperatives through the country, to participate in the school matchmaking, farm fair, so that farmers quality vegetables in supermarket and school directly, but also all the relevant departments for different varieties of vegetables and the supply and demand situation, direct procurement organization of circulation enterprise. At the same time, we also carry out circulation processing and packaging in the local area to prevent frost damage, reduce the losses in the process of re circulation, improve the quality of garden vegetables and strengthen the protection in circulation.

Construct Information Platform. In the information age, information is efficiency. The application of modern logistics information technology in agricultural products logistics, through information interoperability, information sharing, thereby breaking the existing logistics operation mode, reducing the logistics of agricultural products space and time. Sharing through the Internet information platform, fast and efficient access to agricultural products logistics supply and demand both market information, transaction cost and shorten the exploration time, enhance the decision accuracy of logistics enterprises, but also provides a convenient communication channel for both supply and demand of agricultural products, so as to reduce agricultural losses in the choice of logistics, is conducive to scientific control storage and rational allocation of logistics resources, through the establishment of modern logistics information platform of agricultural products, reduce the logistics cost of agricultural products. The logistics information platform of agricultural products 
can provide an important platform support for the protection of agricultural products information. The logistics cost control of agricultural products needs to collect information of various types and angles. Each information is classified and analyzed with purpose, and the method of logistics cost control and management is given. The establishment of logistics information platform can realize the docking of technical information and information exchange and information sharing. At the same time combined with computer network technology, were valuable to the corresponding agricultural products logistics and transportation information, based on the market information effectively determine that the logistics of agricultural products in the rational allocation and reasonable adjustment of traffic and transportation time. Has an important guiding value to establish communication transaction and transaction information platform of the logistics of agricultural products, it uses the transport and storage space, the largest agricultural products logistics in the effective guarantee timeliness has practical value, and has a guiding significance to reduce the logistics cost of agricultural products.

Improve Logistic Facilities. Accelerate the construction of rural logistics infrastructure, improve the logistics of agricultural products in the hardware environment, including the construction of agricultural production, agricultural products into the road of specialization, warehousing and transportation vehicles and tools supporting facilities. Specifically, the government has invested in improving rural road construction, extending roads and railways to agricultural production areas. The use of agricultural subsidies and other policies to increase the popularization and popularization of agricultural specialized logistics vehicles, according to the characteristics of agricultural products, construction of specialized supporting agricultural warehouses. Improve the cold chain logistics infrastructure, build a batch of refrigeration, refrigeration and storage warehouses that meet the needs of modern circulation and consumer demand, and gradually realize the cold chain circulation of fresh agricultural products from origin to table. Modern trading technology, model improve the cold chain logistics mode of fresh agricultural products from the origin to the terminal links. Fresh agricultural products logistics infrastructure, accelerate the spoilage of fresh agricultural products, increase the cost of logistics. We should improve the construction of rural roads, develop more efficient means of transportation, extend highways and railways, and set up storage warehouses and one-stop logistics management facilities in the concentration areas of agricultural products. Only in this way can we realize the modernization and specialization of the facilities, and ensure that consumers can obtain efficient and high-quality fresh agricultural products.

\section{Conclusion}

The optimization of the logistics cost of agricultural products is a systematic project. It requires the state to increase macro control, strengthen investment in agricultural infrastructure and information platforms, and reduce circulation links. The government should encourage free competition in the market to improve the logistics operation system and logistics information system to reduce the logistics cost of agricultural products.

\section{References}

[1] Li Ting, Song Zhilan. Agricultural Products Cold Chain Logistics Cost Accounting Based on ABC [J]. Logistics Engineering and Management, 2014, 36(10): 17-20.

[2] Luo Qingguo. Take Stockholding Leisure Agriculture as the Carrier to Reduce Logistics Cost of Agricultural Products [J]. China Business and Market, 2013(11): 26-31.

[3] He Zhengguang. Study on Cost Accounting of Agricultural Products Logistics [J]. Times Agricultural Machinery, 2017, 44(5): 129-130.

[4] Ou Xiaogang. Study on Strategy for Optimizing Cost Structure of Agricultural Produce Logistics [J]. Logistics Technology, 2013(13): 111-112+115. 